\title{
A Straight-Line Method for Analyzing Residual Drawdowns at an Observation Well
}

\author{
Mesut Çimen \\ Department of Civil Engineering, Faculty of Engineering, Süleyman Demirel University, 32260 Isparta, Turkey \\ Correspondence should be addressed to Mesut Çimen; mesutcimen@sdu.edu.tr
}

Received 20 March 2015; Revised 21 May 2015; Accepted 25 May 2015

Academic Editor: Zdeněk Kala

Copyright (C) 2015 Mesut Çimen. This is an open access article distributed under the Creative Commons Attribution License, which permits unrestricted use, distribution, and reproduction in any medium, provided the original work is properly cited.

Determination of the hydraulic parameters (transmissivity and storage coefficients) of a confined aquifer is important for effective groundwater resources. For this purpose, the residual drawdowns have been in use to estimate the aquifer parameters by the classical Theis recovery method. The proposed method of this paper depends on a straight-line through the field data and it helps to calculate the parameters quickly without any need for long-term pumping data. It is based on the expansion series of the Theis well function by consideration of three terms, and this approach is valid for the dimensionless time factor $u^{\prime}=S^{\prime} r^{2} / 4 T t^{\prime} \leq 0.2$. The method can be applied reliably to extensive and homogeneous confined aquifers resulting in different storage coefficients during the pumping and recovery periods $\left(S \neq S^{\prime}\right)$. It presents a strength methodology for the parameters decision making from the residual data in the groundwater field of civil engineering.

\section{Introduction}

One of the practical ways to estimate the aquifer parameter is to measure the water level rise by time in the production or observation wells after the pumping test stoppage. This is referred to as the recovery test which starts just after the pump shut. The recovery method serves as a check and alternative to the pumping test. The parameters' estimations from both tests are practically equal to each other if the Theis [1] assumptions are satisfied.

The residual drawdown measurement at any time during the recovery period is the difference between the observed water level and the prepumping static water level. The recovery drawdown is known as the difference between the total drawdown at the end of pumping and the residual drawdown $[2,3]$. With the Theis recovery method, the transmissivity can be estimated easily using pumping well recovery data, but the storage coefficient cannot be calculated due to wellbore storage effects, unknown effective radius, and difficulty in finding the time of zero recovery as needed for the application of Cooper and Jacob [4] method. However, in cases of measurements from the observation wells there will not be such restrictive effects. The Theis recovery method considers the late-time residual drawdowns with the Cooper and Jacob formulations and it estimates the transmissivity and the ratio of storativity values during pumping and recovery periods. Theis [1] observed that a straight-line through the residual drawdowns $\left(s^{\prime}\right)$ versus $t / t^{\prime}$ plot $(t$ indicates the total time since pump start while $t^{\prime}$ is the time since pump shut). This plot on the semilogarithmic graph paper passes below the origin $\left(t / t^{\prime}=1, s^{\prime}=0\right)$ giving the value of $t / t^{\prime}>1$ for a zero residual drawdown and that is the reason why different storage coefficient estimations are valid for the pumping and recovery periods. On the other hand, Jacob [5] observed that the storage coefficient estimation is generally greater during the pumping period than the recovery period.

Bruin and Hudson [6] proposed the time-recovery drawdown graph to find the time of zero recovery. The method depends on the extension of the time-drawdown pumping test data, which can also be applied to the time-recovery graph. Later, USDI [7] gave an alternative method for determining the storage coefficient $(S)$ as follows:

$$
S=\frac{2.25 T t^{\prime} / r^{2}}{\log ^{-1}\left[\left(s_{p}-s^{\prime}\right) / \Delta\left(s_{p}-s^{\prime}\right)\right]}
$$

where $T$ is the transmissivity, $s_{p}$ is pumping period drawdown projected to time $t^{\prime}$ at any radial distance, $r, s^{\prime}$ is residual 
drawdown at time $t^{\prime},\left(s_{p}-s^{\prime}\right)$ is recovery at time $t^{\prime}$, and $\Delta\left(s_{p}-\right.$ $\left.s^{\prime}\right)$ is slope of the time-recovery graph. In this formulation $\log ^{-1}[x]$ corresponds to the antilogarithm as $10^{x}$.

The recovery analysis is also investigated by many researchers. For instance, Case et al. [8] developed convenient equations in the forms of a series based on the Theis recovery equation using the residual drawdown data. Agarwal [9] developed a method for recovery test analysis which is widely used by petroleum engineers. Through a simple transformation of the data from a recovery test, Agarwal method allows one to apply the same diagnostic principles and type curves used for drawdown analysis in the interpretation of recovery data. Ramey [10] presented the type curves for drawdown during the pumping and recovery periods, where the recovery times are plotted as large times. Mishra and Chachadi [11] obtained the recovery type curves for large-diameter pumping wells by discrete kernel approach while Şen [12] presented an analytical solution and a set of type curves for the drawdown distribution in a large-diameter well recovery. Later, Yeh and Wang [13] developed a mathematical model for describing the residual drawdown by taking into consideration the pumping drawdown distribution in addition to the effects of well radius and wellbore storage. They obtained the Laplace domain solution for the residual drawdown. Goode [14] proposed a set of graphical recovery type curves based on Theis' [1] exact well-function solution. These type curves depend on the dimensionless duration of pumping. Ballukraya and Sharma [15] proposed an approach derived from the Cooper-Jacob equation for estimating storativity by using residual drawdown measurements. Banton and Bangoy [16] presented a graphical method with the first three terms of the Theis series approximation. The method involves three separate plots with the equality of the storage coefficients in pumping and recovery periods $\left(S=S^{\prime}\right)$, but this approach requires at least two observation wells. Singh [17] proposed a numerical method by considering the derivative of the Theis recovery equation. Zheng et al. [18] suggested a straight-line method based on the Cooper-Jacob approximation for the extended pumping period and the first three terms in the expansion are from the well function for the recovery period. The method considers that $S=S^{\prime}$. Singh [19] presented an optimization method based on nonlinear least-squares for the identification of the transmissivity and the storage coefficients in the pumping and recovery periods. Samani et al. [20] used a derivative analysis of pumping and recovery test data to estimate the hydraulic parameters in a heterogeneous aquifer. They showed that the drawdown-derivative analysis improves estimation of aquifer parameters and identification of different forms of heterogeneity. Kambhammettu and King [21] estimated the transmissivity and storage coefficient using a generalized MATLAB code with the conventional Levenberg-Marquardt algorithm. They considered the residual drawdowns measurements from a single observation well. Ashjari [22] determined the transmissivity and storage coefficients from residual data in case of $S \neq S^{\prime}$ by using a modified version of Banton and Bangoy [15] method. This method is basically fitting a straight-line to a plot of residual drawdown versus square of radial distance at the same time.
In this study, another straight-line method is proposed using the first three terms from the expansion of the well function for the pumping and recovery periods. The method offers the use of spreadsheet for the inequality $S \neq S^{\prime}$, which implies different storage coefficients during pumping and recovery periods. The procedure involves a linear regression line and its coefficients' estimations based on a set of recovery data from a single observation well. It is valid for the dimensionless time factor, $u^{\prime} \leq 0.2$.

\section{Proposed Method}

In a homogeneous isotropic confined aquifer with infinite domain without the well storage, Theis [1] gave the residual drawdown expression for an observation well as follows:

$$
s\left(r, t^{\prime}\right)=\frac{Q}{4 \pi T}\left[\int_{u}^{\infty} \frac{e^{-x}}{x} d x-\int_{u^{\prime}}^{\infty} \frac{e^{-x}}{x} d x\right],
$$

where $s\left(r, t^{\prime}\right)$ is the residual drawdown at any distance $r$ and at any recovery time $t^{\prime}, Q$ is the constant rate (discharge) towards the pumping well during the pumping and recovery periods, $T$ is the transmissivity, $u=r^{2} S / 4 T t$ is the dimensionless time factor for the pumping period, $u^{\prime}=r^{2} S^{\prime} / 4 T t^{\prime}$ is another dimensionless time factor for the recovery period, $S$ and $S^{\prime}$ are the storage coefficients of aquifer during the pumping and recovery periods, $t=t_{p}+t^{\prime}$, and $t_{p}$ is the time of pumping. This expression can be considered after the first three terms of the exponential function series as follows:

$$
\begin{aligned}
& s\left(r, t^{\prime}\right)=\frac{Q}{4 \pi T}[(-0.5772-\ln u+u) \\
& \left.-\left(0.5772-\ln u^{\prime}+u^{\prime}\right)\right], \\
& s\left(r, t^{\prime}\right)=\frac{Q}{4 \pi T}\left[\ln \left(\frac{S^{\prime}}{S} \frac{t}{t^{\prime}}\right)+\frac{r^{2} S^{\prime}}{4 T}\left(\frac{S}{S^{\prime}} \frac{1}{t}-\frac{1}{t^{\prime}}\right)\right] .
\end{aligned}
$$

The error involved in adopting (3b) instead of (2) is less than $1 \%$ for $u^{\prime} \leq 0.2$. Theis [1] proposed the first two terms of the series in (2) by considering that $S / S^{\prime}=1$ in order to estimate the aquifer transmissivity only. Theis approach is valid for $u^{\prime} \leq 0.01$. Hence, $(3 \mathrm{~b})$ considers more recovery data than Theis method. Equation (3b) can be rewritten to estimate the aquifer parameters as

$$
\begin{aligned}
W & =a \tau-b, \\
W & =\frac{s\left(r, t^{\prime}\right)}{1 / t^{\prime}-\left(S / S^{\prime}\right)(1 / t)}, \\
a & =\frac{Q}{4 \pi T}, \\
\tau & =\frac{\ln \left(\left(S^{\prime} / S\right)\left(t / t^{\prime}\right)\right)}{1 / t^{\prime}-\left(S / S^{\prime}\right)(1 / t)}, \\
b & =a \frac{r^{2} S^{\prime}}{4 T} .
\end{aligned}
$$




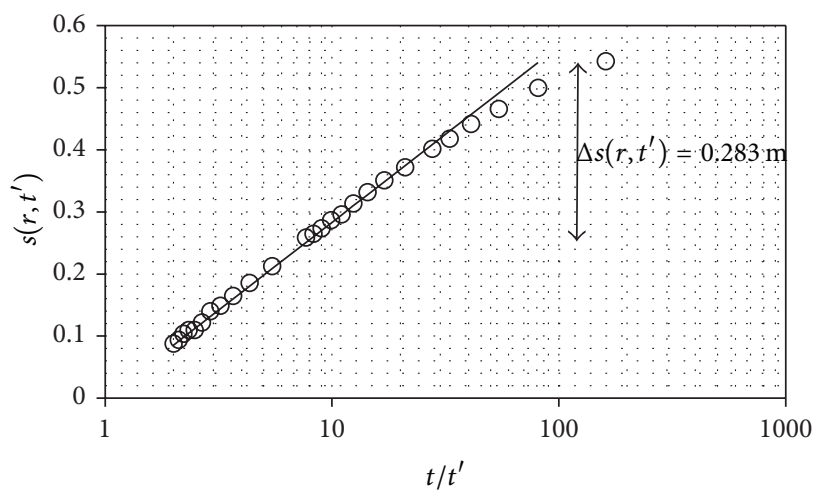

(a)

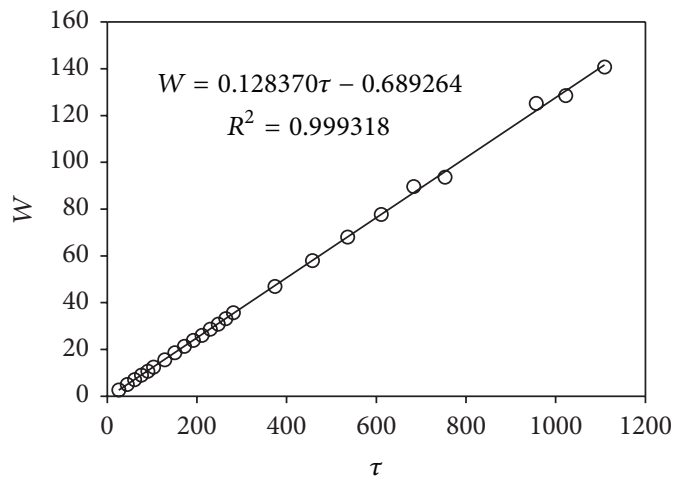

(b)

FIGURE 1: Straight-line fit to recovery data: (a) Theis recovery method and (b) proposed method.

Equation (4) presents a straight-line between $\tau$ and $W$. The first approximation of the aquifer parameter estimations can be obtained from the time residual drawdown data on a spreadsheet with the exception of a few early time instances, and the aquifer parameters can be estimated after fitting a straight-line to the field data and the coefficients of the regression line result from (6) and (8). By considering the calculated parameters, the dimensionless time factors, $u^{\prime}$, should be determined especially for the first data values. If $u^{\prime}$ is greater than 0.2 , then the straight-line should be rearranged. Furthermore, the ratio of $S / S^{\prime}$ may be easily investigated with various straight-lines.

\section{Application and Discussion}

Two data sets are used to illustrate the application of the proposed method. The first set of data is taken from the USDI [7]. The data is recorded in an observation well located at $30.48 \mathrm{~m}$ from the pumping well. The well is pumped during $800 \mathrm{~min}$ with a constant discharge rate of $4.613 \mathrm{~m}^{3} / \mathrm{min}$, and the recovery period is also recorded as $800 \mathrm{~min}$ after the pump is turned off. The last record of pumping data is $0.567 \mathrm{~m}$ at $800 \mathrm{~min}$. USDI [7] estimated the transmissivity as $2.982 \mathrm{~m}^{2} / \mathrm{min}$ with the Theis recovery method (for $S=S^{\prime}$ and $\left.u^{\prime} \leq 0.01\right)$ and the storage coefficient as 0.07 according to (1) (for $\left(s_{p}-s^{\prime}\right)=0.533 \mathrm{~m}$ and $\Delta\left(s_{p}-s^{\prime}\right)=0.302 \mathrm{~m}$ ). Figure $1(\mathrm{a})$ explicitly shows a difficulty at fitting a straight-line to the data on a semilogarithmic graph plot between residual drawdown and $t / t^{\prime}$. By the application of (5) and (7) for $S / S^{\prime}=1$ to the observed recovery data except for the data at $t^{\prime}=0,540$, and $600 \mathrm{~min}$ and after fitting a straight-line, a relationship similar to (4) is obtained (Figure 1(b)). From the straight-line parameters, the transmissivity and the storage coefficients are calculated as $2.8596 \mathrm{~m}^{2} / \mathrm{min}$ and 0.0661 , respectively. For $u^{\prime}=0.2$, the recovery time, $t^{\prime}$, is determined as $26.8 \mathrm{~min}$ from these estimations. For this reason, the data after $26.8 \mathrm{~min}$ is reconsidered, and the transmissivity and the storage coefficients are recalculated as $2.8594 \mathrm{~m}^{2} / \mathrm{min}$ and 0.0666 (for $a=0.12838$ and $b=0.694922$ ), respectively. These parameters yield $0.568 \mathrm{~m}$ as a close value to $0.567 \mathrm{~m}$,

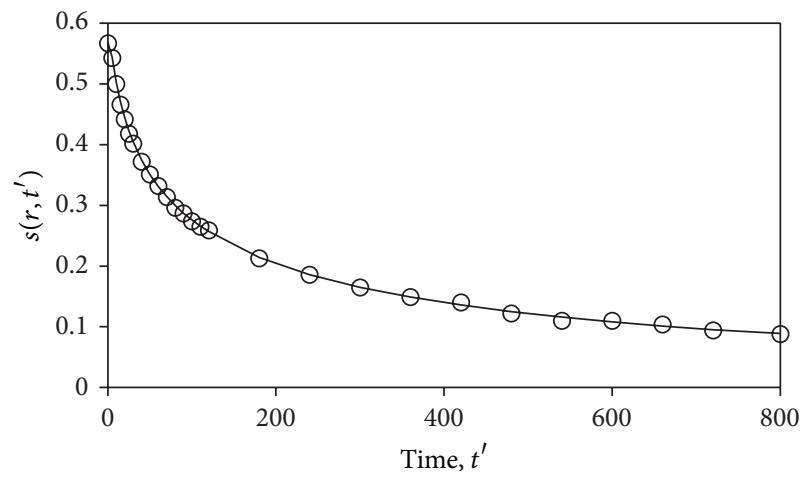

FIgURE 2: Observed and simulated residual drawdowns.

which is the last drawdown at $t=800 \mathrm{~min}$ during the pumping period. According to USDI's [7] parameter values, the last drawdown is $0.544 \mathrm{~m}$, which is far away from $0.567 \mathrm{~m}$. Zheng et al. [18] method $\left(T=2.855 \mathrm{~m}^{2} / \mathrm{min}\right.$ and $\left.S=0.0696\right)$ which uses a straight-line similar to the proposed methodology produces $0.563 \mathrm{~m}$. The reason of the difference between the values of Zheng et al. [18] and the methodology of this paper may be due to the lack of $S / S^{\prime} t$ in the right-side of (3b). Figure 2 shows the measured and simulated residual drawdowns versus time.

The second set of recovery data is produced synthetically for $Q=3 \mathrm{~m}^{3} / \mathrm{min}, r=50 \mathrm{~m}, t_{p}=70 \mathrm{~min}, s\left(r, t_{p}\right)=0.396 \mathrm{~m}$, $T=1 \mathrm{~m}^{2} / \mathrm{min}, S=0.0055$, and $S^{\prime}=0.005$. Table 1 shows the residual drawdowns for this data. Figure 3(a) presents a nonlinear relation between $\tau$ and $W$ for $S=S^{\prime}$, while Figure 3(b) shows a linear relation for $S / S^{\prime}=1.1$. Figure 3(a) implies that the rate of $S / S^{\prime}$ has a big effect on the late-time residual drawdowns during the recovery period. From the straightline parameters at Figure 3(b), the transmissivity and the storage coefficients during the recovery and pumping periods are calculated as $1.0 \mathrm{~m}^{2} / \mathrm{min}$ from (6), 0.0048 from (8), and 0.0053 from $S / S^{\prime}=1.1$, respectively. For $u^{\prime}=0.2$, the recovery time, $t^{\prime}$, is determined as $14.99 \mathrm{~min}$ from these estimations $\left(T\right.$ and $S^{\prime}$ ). For this reason, the data after $14.99 \mathrm{~min}$ 


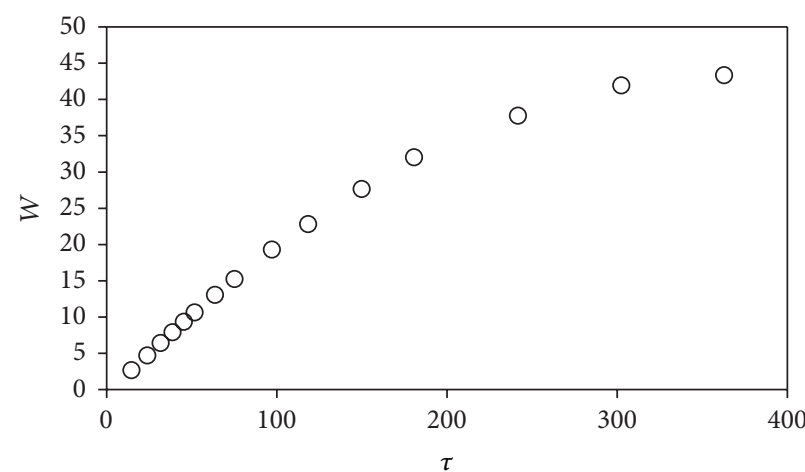

(a)

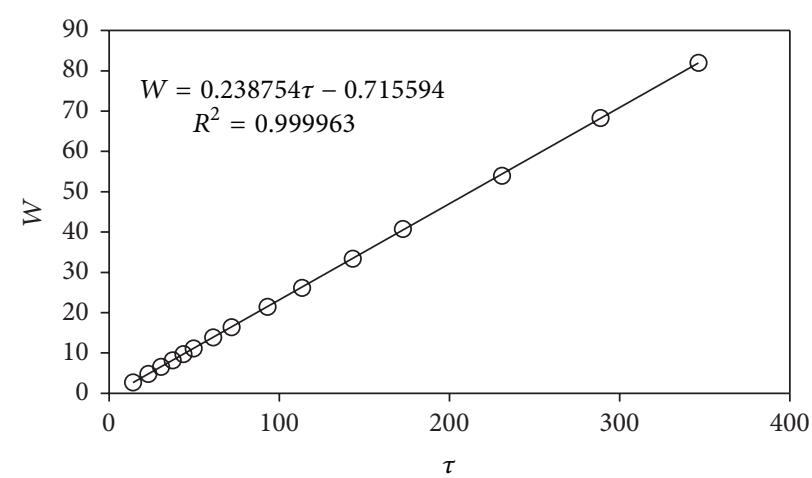

(b)

Figure 3: Plots of $W$ versus $\tau$ of the synthetic data: (a) for $S=S^{\prime}$ and (b) straight-line fit to recovery data for $S / S^{\prime}=1.1$ and fitting parameters.

TABLE 1: Synthetic residual drawdowns.

\begin{tabular}{lc}
\hline$t^{\prime}(\mathrm{min})$ & $s\left(r, t^{\prime}\right)(\mathrm{m})$ \\
\hline 0 & 0.593 \\
5 & 0.506 \\
10 & 0.415 \\
15 & 0.354 \\
20 & 0.309 \\
25 & 0.276 \\
30 & 0.249 \\
40 & 0.208 \\
50 & 0.178 \\
70 & 0.138 \\
90 & 0.111 \\
120 & 0.085 \\
150 & 0.068 \\
210 & 0.045 \\
270 & 0.032 \\
330 & 0.023 \\
\hline
\end{tabular}

is reconsidered, and the transmissivity and storage coefficients are found as $1.0 \mathrm{~m}^{2} / \mathrm{min}, 0.00494$, and 0.00543 (for $a=$ 0.238856 and $b=0.737662)$, respectively. The errors in the obtained storage coefficients with respect to the other storage coefficients are due to the rounded recovery values, which are calculated from (2).

\section{Conclusion}

An effective method has been proposed for decision making to the transmissivity and storage coefficients estimations from the residual drawdowns during the recovery period. The methodology is valid for the confined aquifers and considers the expanding series of Theis well function with the first three terms and the maximum dimensionless time as $u^{\prime} \leq 0.2$. This approach considers a lot of residual drawdown data than the classical Theis recovery method. The procedure depends on a straight-line through the field data and calculates rather easily the aquifer parameters without the pumping data (if it is unavailable). Validity of the procedure is presented by considering actual field data, while the Theis recovery method has some difficulties at fitting a straight-line to a given field data. This method of this paper is very effective for the aquifer parameters estimation and it can be reliably applied to the residual data at an observation well in the extensive and homogeneous confined aquifers with different storage coefficients during the pumping and recovery periods $\left(S \neq S^{\prime}\right)$.

\section{Conflict of Interests}

The author declares that there is no conflict of interests regarding the publication of this paper.

\section{References}

[1] C. V. Theis, "The relation between the lowering of the piezometric surface and the rate and duration of discharge of a well using ground-water storage," Transactions, American Geophysical Union, vol. 16, no. 2, pp. 519-524, 1935.

[2] Z. Şen, Applied Hydrogeology for Scientists and Engineers, CRC Press, New York, NY, USA, 1995.

[3] V. Batu, Aquifer Hydraulics: A Comprehensive Guide to Hydrogeologic Data Analysis, John Wiley \& Sons, New York, NY, USA, 1998.

[4] H. H. Cooper and C. E. Jacob, "A generalized graphical method for evaluating formation constants and summarizing well-field history," Transactions, American Geophysical Union, vol. 27, no. 4, pp. 526-534, 1946.

[5] C. E. Jacob, "The recovery method for determining the coefficient of transmissibility," in Methods of Determining Permeability, Transmissibility and Drawdown, USGS Water Supply Paper 1536-I, pp. 283-292, 1963.

[6] J. Bruin and H. E. Hudson, Selected Methods for Pumping Test Analysis, Report of Investigation no. 25, Illinois State Water Survey, Champaign, Ill, USA, 1955.

[7] USDI, Ground Water Manual, US Department of Interior, Bureau of Reclamation, Washington, DC, USA, 1981.

[8] C. M. Case, W. W. Pidcoe, and P. R. Fenske, "Theis equation analysis of residual drawdown data," Water Resources Research, vol. 10, no. 6, pp. 1253-1256, 1974. 
[9] R. G. Agarwal, "A new method to account for producing time effects when drawdown type curves are used to analyze pressure buildup and other test data," in Proceedings of the 55th Annual Fall Technical Conference and Exhibition of the Society of Petroleum Engineers, SPE Paper 9289, 1980.

[10] H. J. Ramey, "A drawdown and build-up type curve for interference testing," in Proceedings of the 3rd Invitational Well-Testing Symposium, T. W. Doc and W. J. Schwarz, Eds., pp. 130-134, Berkeley, Calif, USA, 1980.

[11] G. C. Mishra and A. G. Chachadi, "Analysis of flow to a largediameter well during the recovery period," Ground Water, vol. 23, no. 5, pp. 646-651, 1985.

[12] Z. Şen, "Drawdown distribution during recovery around a large diameter well," Nordic Hydrology, vol. 22, no. 4, pp. 253-264, 1991.

[13] H.-D. Yeh and C.-T. Wang, "A semianalytical solution for residual drawdown at a finite diameter well in a confined aquifer," Journal of the American Water Resources Association, vol. 49, no. 4, pp. 966-972, 2013.

[14] D. J. Goode, "Composite recovery type curves in normalized time from Theis' exact solution," Ground Water, vol. 35, no. 4, pp. 672-678, 1997.

[15] P. N. Ballukraya and K. K. Sharma, "Estimation of storativity from recovery data," Ground Water, vol. 29, no. 4, pp. 495-498, 1991.

[16] O. Banton and L. M. Bangoy, "A new method to determine storage coefficient from pumping test recovery data," Ground Water, vol. 34, no. 5, pp. 772-777, 1996.

[17] S. K. Singh, "Storage coefficient and transmissivity from residual drawdowns," Journal of Hydraulic Engineering, vol. 129, no. 8, pp. 637-644, 2003.

[18] L. Zheng, J.-Q. Guo, and Y. Lei, "An improved straight-line fitting method for analyzing pumping test recovery data," Ground Water, vol. 43, no. 6, pp. 939-942, 2005.

[19] S. K. Singh, "Identification of aquifer parameters from residual drawdowns: an optimization approach," Hydrological Sciences Journal, vol. 51, no. 6, pp. 1139-1148, 2006.

[20] N. Samani, M. Pasandi, and D. A. Barry, "Characterizing a heterogeneous aquifer by derivative analysis of pumping and recovery test data," Journal of Geological Society of Iran, vol. 1, pp. 29-41, 2006.

[21] B. V. N. P. Kambhammettu and J. P. King, "Estimation of aquifer parameters from residual drawdowns," Proceedings of the Institution of Civil Engineers: Water Management, vol. 163, no. 7, pp. 361-365, 2010.

[22] J. Ashjari, "Determination of storage coefficients during pumping and recovery," GroundWater, vol. 51, no. 1, pp. 122-127, 2013. 


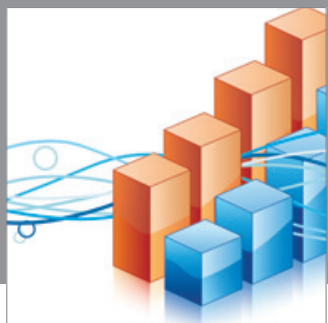

Advances in

Operations Research

mansans

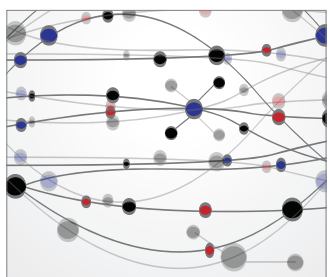

The Scientific World Journal
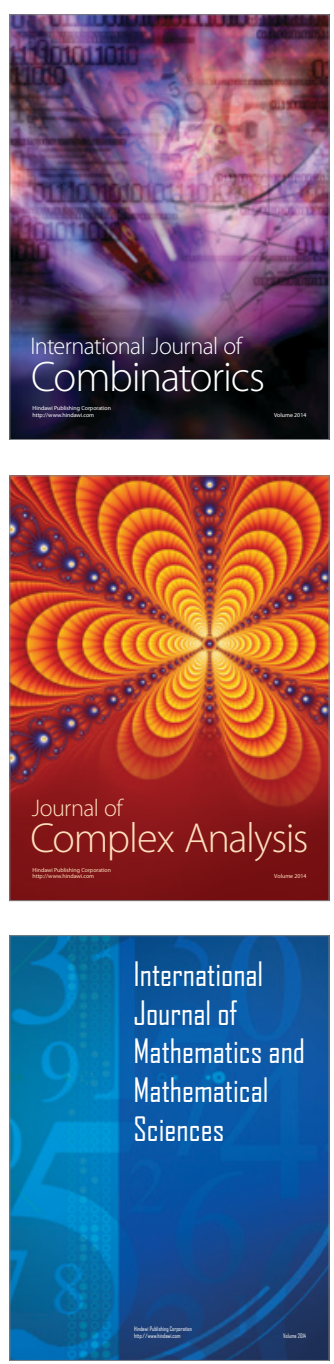
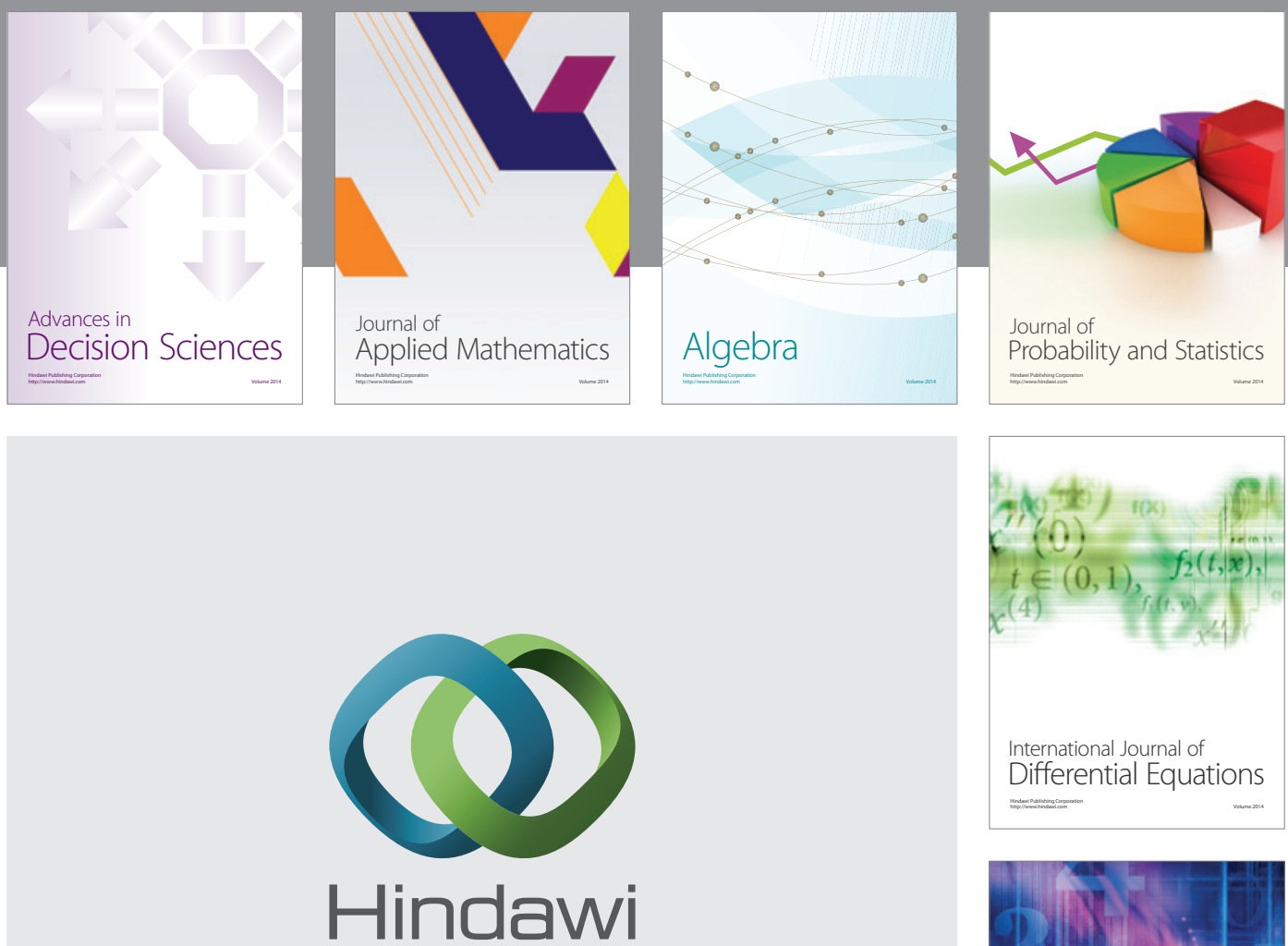

Submit your manuscripts at http://www.hindawi.com
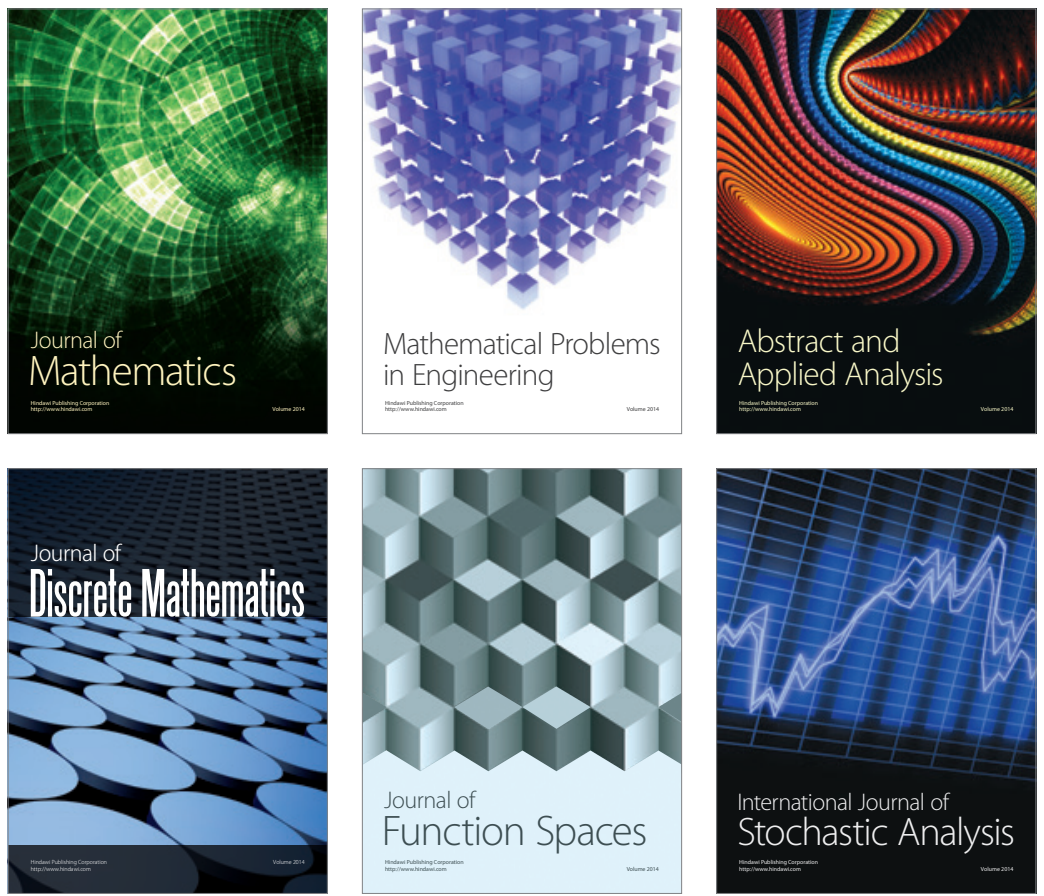

Journal of

Function Spaces

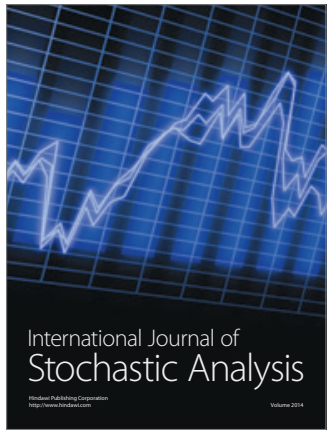

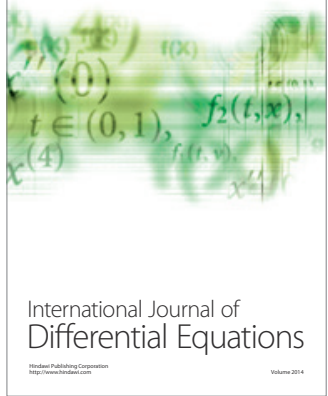
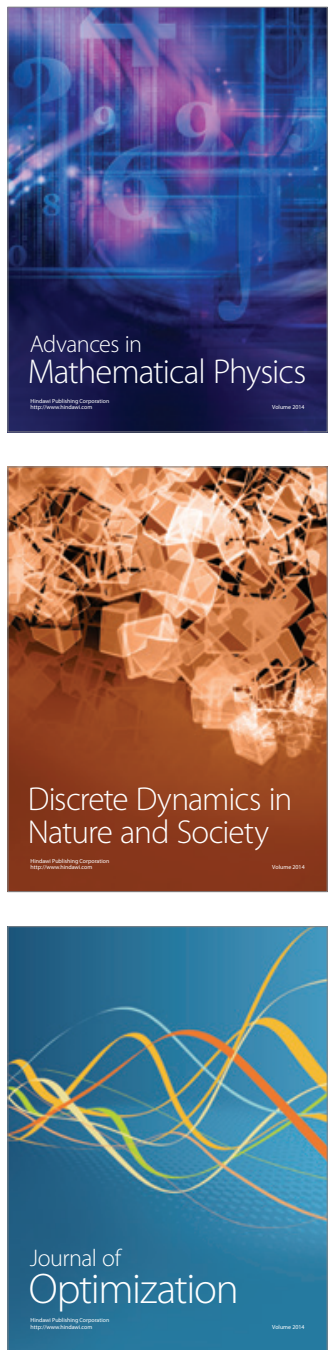